\title{
Smart Health Informatics System
}

\author{
Phong Thanh Nguyen, M. Ilayaraja, K. Shankar, Wahidah Hashim, Andino Maseleno
}

\begin{abstract}
The smart health informatics system give data about health, compilation, analyses and generation also provide secure data for system development and safe policy. Health informatics system in relies upon quality, cost and efficiency of healthcare system. The smart health informatics system has positive influences on health but some failures and difficulties are there, that need to concern in future research. For better coordinate of Healthcare the smart health informatics system consider as an important component. This system emphasis on proper transmission, retrieval, generation and storage of health data. A good decision making is necessary for making a relevant, timely health and accurate smart health informatics system.
\end{abstract}

Keywords : Health informatics systems, Hospital information systems, healthcare, Health information technology, Information Technology.

\section{INTRODUCTION}

The healthcare services benefits that are give the administrations to treatment, determination, and anticipation structure sicknesses and constrained by the great supervisory crew can be consider as smart health care [1][2]. By interfacing human services with information technology this sort of framework give information to tolerant whenever or wherever. Advanced change is essential in brilliant smart health field.Smart wellbeing consolidated with a comprehensively flexible clinical data document that is determinedly eHealth benchmarks steady, offers an extent of off-the-rack meandering thought and the other open and private eHealth frameworks associated with it [3].

The smart health care informatics system provides many functions like compilation, communication, data generation, analysis and synthesis of data. It is very necessary to provide a proper transmission, retrieval, generation and storage of health data. For smart health care informatics system a good decision making required relevant, on time and accurate information [4] [5].

Due to tremendous enhancement of population the previous healthcare system cannot accommodate the need of every one. The medical services cannot afford and approach

Revised Manuscript Received on July 22, 2019.

* Correspondence Author

Phong Thanh Nguyen*, Department of Project Management, Ho Chi Minh City Open University, Vietnam. E-mail phong.nt@ou.edu.vn

M. Ilayaraja, Department of Computer Science and Information Technology, Kalasalingam Academy of Research and Education, Krishnankoil, India. E-mail: ilayaraja.m@klu.ac.in

K. Shankar*, Department of Computer Applications, Alagappa University, Karaikudi, India. E-mail: shankarcrypto@gmail.com

Wahidah Hashim, Institute of Informatics and Computing Energy, Universiti Tenaga Nasional, Malaysia

Andino Maseleno, Institute of Informatics and Computing Energy, Universiti Tenaga Nasional, Malaysia.. by everyone because of cutting-edge technologies and having excellent infrastructure. The main aim of smart health care informatics system is to provide education about their health status and keep them aware about their health issues [6].

For any government health is a major issue on which they should concern. In past few years the studies about healthcare system are developed and researches shows their keen interest to developing an efficient and accurate informatics system [7].

\section{LITERATUE SURVEY}

In the old period the medical history of any patient is recorded on paper. Since it was straightforward for utilizing, it was solid and the cost was low. At the point when the restorative experts thinking about a patient the Information might be shared and immediately included. Due to decentralize nature of the medicinal services framework there were numerous issues emerge. There were exceptionally hard to get the record of patient when it visits various workplaces treatment like essential consideration, cardiology, dental work, and so forth. Deficient and Fragmented record of patient made issues in legitimate consideration of patients. So there is have to build up an electronic based savvy wellbeing record that can take care of the issues identified with record that were generally saved money on papers.

The research shows that there are several literature surveys are available about smart healthcare informatics system. For interoperability testing of healthcare applications in [8] [9] the researcher introduced a TTCN-3 standard which was based on test platform. For improving performance of healthcare informatics systems paper [10] proposed a new XML-aware compression technique. In [11] the author described a framework for interoperable healthcare informatics systems in order to manage complex medical data. For mobile or cloud enabled and conceptualizing data-driven smart healthcare systems a Smart Healthcare Systems Framework is defined in [12]. To homogeneous management and enables standardized exchange of ECG formats another healthcare informatics system is described in [13].

\section{CLASSIFICATION OF SMART HEALTHCARE SYSTEM}

As previously defined that smart health is provide a digital healthcare solution, which can controlled remotely. Mobile-health and telemedicine and collectively known as smart health. Smart health provides automatic continuous monitoring of health; alter suitable solution and emergency detection. For enhancing the 
efficiency and quality of healthcare the connected health system enable self-care services and can operate with remote access. It is used in the area of telemedicine, where the user knows about its health and when it required provide the feedback. The system of smart healthcare provide a complete solution of operate autonomously; when it require a feedback solutions from the clinicians it can directly connected to them. For people or hospitals based on cost, architecture and power the healthcare network can be developed [14].

The classification of smart healthcare system is shown in figure. The basic classification is based on medical devices, system management, technologies used, end users and services. The connecting technology play major role in

1. Expand the application for which healthcare system designed

2. Smart Health Care Classification [15].

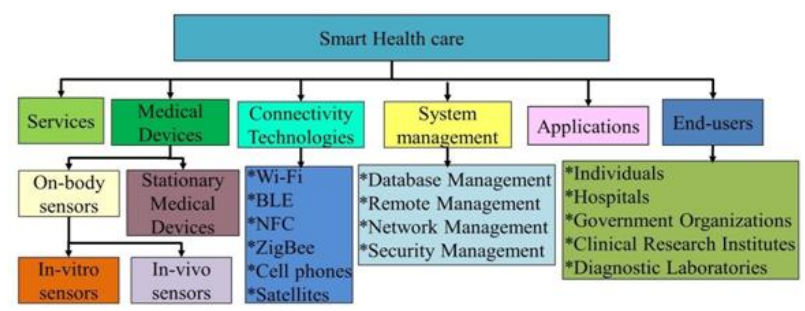

FIGURE 1: SMART HEALTH CARE SYSTEM CLASSIFICATION

\section{IT CONVERGENCE ON THE HEALTHCARE SYSTEM}

The ideal healthcare system paradigm is shown in figure given below. For an ideal healthcare system network technology, data processing technology and sensor technology are required. Diagnostic software, electronic health record systems and digital imaging processing is including in data processing. By using the concept of the Internet of Things ( IoT) the researchers offered many benefits in improving the quality of care and field of medicine [16-18]. In health care system in various possible components many researcher try to expand the concept of IoT [19-21].

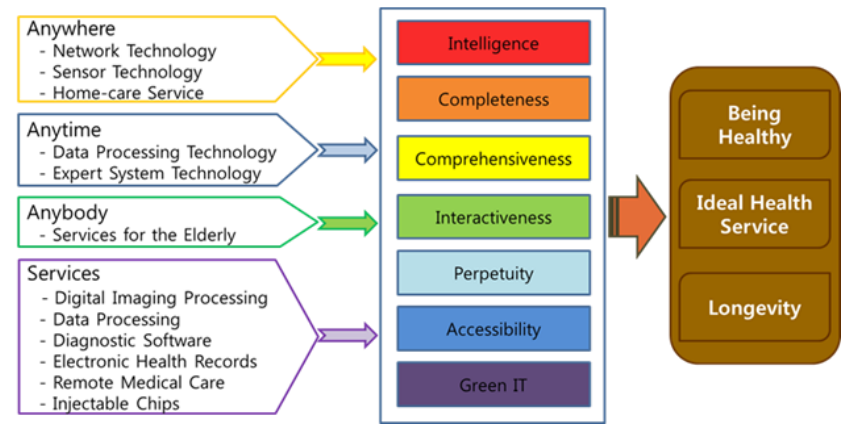

Figure 2: ideal healthcare system Paradigm

To transfer and acquire the medical data first element is a medical sensor device. The 2 nd element is software that behaves like a virtual medical sensor, having big-data analysis and intelligent diagnosis algorithm. Mobile application is the 3rd element. Mobile application used for browsing medical data about user or patients from medical
IoT device. Platform and its manager are considered as 4th element. By using interoperable software all components can connect to each other using platform [22].

\section{INTERNET OF THINGS FOR SMART HEALTHCARE INFORMATICS SYSTEM}

By providing remote access the by providing remote access behave like bridge between patient and medical professionals. It helps the medical professionals to monitor continuously about health of patient and can provide remote consultation. IoT helps to make healthcare available to everyone and it provide efficient and accurate outcome by using actuators, processors, sensors, microcontrollers and cloud computing.

The IOT is considering as new field of research and there is lots of area which have to be developed. By using machine to machine communication a network device that use to interact with each other is known as Internet of Things. This device enables exchange and collection of data [23-25]. This technology use for collection of large amount of data and it allows the automation with wide range of industries.

\section{Internet of Things in Healthcare}

By using IOT anyone, anywhere connected to Healthcare ubiquitous services, including small or large healthcare facilities, buildings and personal space. On online consultancy or alert generation, ambulatory services, emergency situations and planned schedules, it covers the clinical management of patients. The IOT platform provides a large variety of data [26].

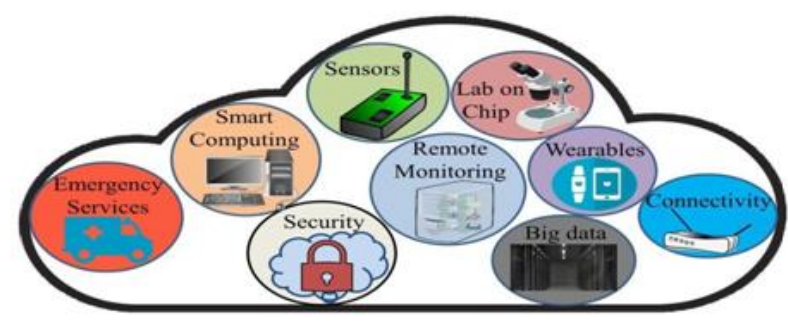

Figure 3: IOT in smart healthcare

\subsection{SMART HEALTHCARE SYSTEM INFORMATIC SYSTEM COMPONENTS}

The main component of IOT based smart healthcare informatics system is sensor technology. The technology used for collecting the data. The 2 nd component is known as an intelligent network. After collecting the data, to communicate with the system data goes to an intelligent network. The 3rd component is the cloud computing. Cloud computing use to store the data. When the system gets proper result of the data then the useful information is sent to healthcare professionals. In this way the information collected by 1 st component as a part of circular system. 


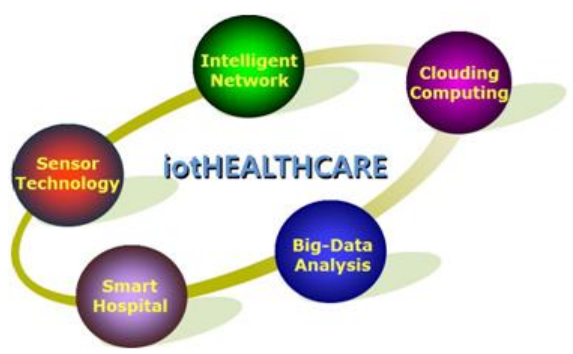

Figure 4: IOT HEALTHCARE informatics system components

\subsection{ARCHITECTUREOF IOT HEALTHCARE INFORMATIC SYSTEM}

It is necessary to know about the characteristics of each component to achieve the smart healthcare informatics system. The characteristics are:

- Reliability- to transform dynamic data into valuable information Big-data analysis requests reliability

- Continuity - for intelligent network Interoperability support requests continuity to communicate with internet, among each other and user

- Integrity- to assure that the data that user send or receive cannot be compromised or altered it is required.

- Efficiency- for proper treatment and diagnosis Smart hospital requests efficiency

- Confidentiality- in smart healthcare informatics system this is very necessary because to save dynamic data in cloud computing require confidentiality in powerful storage for computing resource.

- Stability: for trustworthy data collection of sensor technology Continuous real-time monitoring requests stability

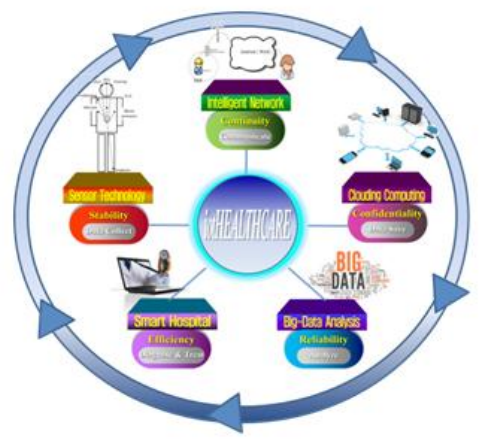

Figure 5: IOT based on HEALTHCARE informatics system

\section{SMART HEALTHCARE INFORMATIC RECORDS}

In computerized design when patient information are put away electronically then this is known as smart healthcare informatics system. These smart records can access by a few other medicinal services frameworks. These records can be shared through other data systems and trades, undertaking wide data framework and system association. These records have wide information of therapeutic history, radiology pictures, individual measurements like weight, charging data and age, socioeconomics, prescription and sensitivities, vaccination status, lab test outcomes and so forth. architecture

For expanding the nature of consideration of patients the keen smart health informatics records are created. Through the consideration the executives programs the supplier use information from records of patients. For improving the adequacy and nature of human administrations the related wellbeing records engage self-care benefits and can work with remote access. The record of smart healthcare give a complete plan of work independently; when it require an info game plans from the clinicians it can clearly connected with them. For people or restorative facilities subject to cost, plan and power the therapeutic administrations framework can be made [27].

It is extremely important to give a safe patient record in social insurance division. In any case, foundations of wellbeing move toward improved access.

It is vital for social healthcare institutions to the security and reliability of patient information. it is at present an authentic essential. Regardless, in shrewd wellbeing records it is troublesome. The security of record of Patient is significant in light of the fact that by and large like HIV status because of clever thought could achieve social disgrace, renouncing of wellbeing points of interest and loss of business. Also on the off chance that it gives unapproved access to charging information, at that point it very well may be the reason for money related misfortunes for patients.

\section{CONCLUSION}

The smart health informatics system give information about wellbeing, accumulation, investigations and age additionally give secure information to framework advancement and safe arrangement. smart health informatics system in depends upon quality, cost and effectiveness of social insurance framework. The shrewd wellbeing informatics framework has positive impacts on wellbeing yet a few disappointments and challenges are there, that need to worry in future research. For better arrange of Healthcare the smart health informatics system consider as a significant segment. This framework accentuation on legitimate transmission, recovery, age and capacity of wellbeing information. A decent basic leadership is fundamental for making a pertinent, opportune wellbeing and precise keen wellbeing informatics system. The social insurance administrations benefits that are give the organizations to treatment, assurance, and expectation structure infections and compelled by the incredible supervisory team can be consider as smart health care.

\section{ACKNOWLEDGMENT}

This article has been written with financial support of RUSA-Phase 2.0 grant sanctioned vide Letter No. F. 24-51/2014-U, Policy (TNMulti-Gen), Dept. of Edn. Govt. of India, Dt. 09.10.2018.

\section{REFERENCES}

1. O. Sebetci and M. Aksel(2016)."An Overview of the Studies of Health Information Systems in Turkey".vol. 4,no.8, pp. 100-106. 


\section{Smart Health Informatic System}

2. Australian Institute of Health and Welfare,"Australia's Health,” 2014. [Online].

Available:http://www.aihw.gov.au/WorkArea/DownloadAsset.aspx-?id $=60129548150$

3. E. Perrier(2015)."Positive Disruption: Healthcare, Ageing \&Participation in the Age of Technology". Australia: TheMcKell Institute.

4. World Health Organization (2008) Health Metrics Network Framework and Standards for Country Health Information Systems. World Health Organization.

5. World Health Organization (2008) Health Information Systems. World Health Organization.

6. S. P. Mohanty, U. Choppali and E. Kougianos(2016)."Everything you wanted to know about smart cities: The Internet of things is the backbone".IEEE Consumer Electronics Magazine, vol. 5, no. 3, pp. 60-70.

7. (2011)"Turkish Demographic and Health Survey". Turkey DHS final report. Ankara, Hacettepe University Institute of Population Studies.

8. Vega, D.E., Schieferdecker, I. and Din, G. (2010)."Design of a Test Framework for Automated Interoperability Testing of Healthcare Information Systems". 2nd International Conference on eHealth, Telemedicine, and Social Medicine,2010. ETELEMED'10, 10-16 February 2010, pp. 134-140.

9. Vega, D.E. (2010)."Towards an Automated and Dynamically Adaptable Test System for Testing Healthcare Information Systems". 3rd International Conference on Software Testing, Verification and Validation, 331-334.http://dx.doi.org/10.1109/ICST.2010.67

10. Al-Shammary, D. and Khalil, I(.2010) "A new XML-Aware Compression Technique for Improving Performance of Healthcare Information Systems over Hospital Networks". 32nd Annual International Conference on Engineering in Medicineand Biology Society (EMBC), 31 August-4 September 2010, pp.4440-4443.

11. Kumar, C.S., Rao, C.V.G. and Govardhan, A. (2010). "A Framework for Interoperable Healthcare Information Systems".International Conference on Computer Information Systems and Industrial Management Applications (CISIM), 8-10 October 2010, pp. 604-608.

12. Demirkan, H. (2013). "A Smart Healthcare Systems Framework". IEEE IT Professional, vo.15, pp. 38-45.

13. jesús Daniel Trigo, Ignacio Martínez, Álvaro Alesanco, Alexander Kollmann, Javier Escayola, Dieter Hayn and José García(2012). "An Integrated Healthcare Information System for End-to-End Standardized Exchange and Homogeneous Management of Digital ECG Formats". IEEE Transactions on Information Technology in Biomedicine, vo.16, issue. 4, pp. 518-529.

14. Prabha Sundaravadivel, Elias Kougianos, Saraju P. Mohanty and Madhavi Ganapathiraju(2018)."Everything You Wanted to Know about Smart Health Care: Evaluating the Different Technologies and Components of the Internet of Things for Better Health".

15. K. Ullah, M. A. Shah and S. Zhang(2016)."Effective ways to use Internet of Things in the field of medical and smart health care". in Proceedings of the International Conference on Intelligent Systems Engineering (ICISE).pp. 372-379.

16. Keh HC, Shih CC, Chou KY, Cheng YC, Ho HK, Yu PY and Huang $\mathrm{NC}(2014)$. "Integrating unified communications and Internet of M-Health things with micro wireless physiological sensors". Journal of Applied Science and Engineering. vol. 17, no.3,pp. 319-28.

17. Santos A, Macedo J, Costa A and Nicolau MJ(2014). "Internet of Things and smart objects for M-Health monitoring and control". Procedia Technology. Vol.16, pp.1351-1360.

18. Amendola S, Lodato R, Manzari S, Occhiuzzi C and Marrocco G(2014). "RFID technology for IoT-based personal healthcare in smart spaces". IEEE Internet of Things Journal. vo.1, no.2, pp.144-52.

19. Lee BM(2014). "Design requirements for IoT healthcare model using an Open IoT platform". Advanced Science and Technology Letters.pp.69-72.

20. Yang G, Xie L, Mantysalo M, Zhou X, Pang Z, Xu LD, Kao-Walter S, Chen Q and Zheng LR(2014). "A Health-IoT platform based on the integration of intelligent packaging, unobtrusive bio-sensor and intelligent medicine box". IEEE Transactions on Industrial Informatics. vo.10, no.4, pp.2180-2191.

21. Pedro Diogo, Luís Paulo Reis and Nuno Vasco Lopes (2014).’Internet of Things: A System's Architecture Proposal".

22. Shaftab Ahmed, Mohammad Ilyas and M. Yasin Akhtar Raja(2018)."Internet of Things: Applications in Smart
Healthcare".Proceedings of The 9th International Conference on Society and Information Technologies.

23. ]https://blog.technavio.com/blog/top-5-healthcare-technologies-changingglobal-smart-healthcare-market. 